\title{
TRANSPORT-TOURISM INTEGRATED DEVELOPMENT
} ACCESSIBILITY ANALYSIS BASED ON COST AND TOURISTIC ATTRIBUTES

\author{
Domenico Gattuso $^{1}$, Margherita Malara ${ }^{2}$ \\ ${ }^{1}$ Full Professor of Transportation Planning, Dep. DIIES, Mediterranea University of Reggio Calabria, Reggio \\ Calabria, Italy \\ ${ }^{2}$ PhD Student, Dep. PAU, Mediterranea University of Reggio Calabria, Reggio Calabria, Italy
}

\begin{abstract}
In tourism activity the concept of travel is implicitly included and a relationship is implied with the transport system. The planning of measures in transportation field pushes to analyze the mobility demand, and touristic component, related to the socio-economic variables that characterize a region and to the transport system performances. On the other hand, the tourist policies cannot neglect the related aspects to the management of the individuals movements toward the regions and inside the same regions. The coordinated promotion of investments in the tourist industry and in transport sector may encourage a better access to the sites and the reduction of the travel costs. In this regard, the analysis of the Transport-Tourism system, by specific accessibility models, may represent a decision system tool to orient choices of economic policies. In the paper, a preliminary review of reference models is illustrated, taken back by the specialized literature. The attention is specifically focused on the accessibility models. Therefore a theoretical approach of accessibility analysis is proposed, able to include both factors of travel cost and touristic attractiveness. This approach is applied to a context of international tourism, useful to put in evidence the role of the different components involved.
\end{abstract}

Keywords: - Transport models, Accessibility, Travel cost, Tourism, Impacts

\section{INTRODUCTION}

Tourism includes the activities of persons travelling to and staying in places outside their usual environment for not more than one consecutive year for leisure, business or other purposes [1]. Tourism is one of the most important industries, and its impacts on the social and economic life is very relevant.

The tourism sector, at international level, lives a positive dynamic. In the last years a growth the international tourism travels has been registered and the trend is estimated to keep globally positive, around $4 \%$ on average, up to 2030 . The increasing trend concerns almost all macro-geographical areas, but Europe has the most consistent share of arrivals (over $50 \%$ ), equal to 600 million travelers.

It is estimated that this international tourism produced overall expenditure in 2016 totaling 1.141,5 bn $€$. Europe has the most relevant share $(36,4 \%$ of the total) if this expenditure is divided by geographical macro-areas.

The World Travel \& Tourism Council [2] estimates the travel and tourism sector contributes for $10,2 \%$ of global Gross Domestic Product (GDP), around USD 6.203,3 bn $€$ (10,2\% of GDP), and that it provided directly for 109 million jobs in 2016, equal to $3,6 \%$ of total world employment, and will account for 136 million jobs by 2026 .
Further growth in employment is expected: it is forecast to rise by $3,9 \%$ p.a. to $9.380,1$ bn $€(11,4 \%$ of GDP) in 2027 , which would bring the total number of employees up to around 150 million in 2026 with an average annual increase of $2,9 \%$ over the next decade. Travel and tourism investment in 2016 was 657 bn $€$, or $4,4 \%$ of total investment. It should rise by $4,5 \%$ p.a. over the next ten years to USD $1.064,81$ bn $€$ in 2027 (5,0\% of total).

Accurate prediction of foreign tourist numbers has become crucial for governments to be able to set up relevant sustainable tourism development and marketing strategies to promote the tourism industry. National authorities are always more interested to the characteristics and trends of foreign tourists. The variety of international tourism has raised a challenging task for foreign tourist prediction.

Practices and Geographies of destinations changed massively in the last 30 years. Today we witness a form of global tourism; it has spread since the early 90 s to today and now extends to all social classes. The prevalent forms of tourism are holidays; visiting friends and relatives; business related; pilgrimages; health; sport; educational study; etc.; but some new typologies that foresee a more authentic contact with the local reality (rural, environmental, cultural, religious, eno-gastronomic tourism) tend to emerge. For these reasons, the supply is oriented to meet the demand through the enhancement of resources and local identities, 
integration and shared development (involvement of local actors), differentiation, personalization and specialization, taking into account the demand (consumer interest), fashions, lifestyle changed) and new technological opportunities, especially in terms of information and communication.

Global flows are increasing, although for limited periods of time; the holiday periods are distributed throughout the year, multiplying the opportunities for recreation, organized in short stays, a few days or even just a weekend; parks and nature reserves attract more and more visitors as they satisfy the need for quiet and natural environments; group travels are abandoned; destinations far from the classic, uncrowded, are chosen; rural traditions arouse attention and curiosity; the tourist demand asks for a global supply.

Over the years it has been consolidating the awareness that the development of the tourism economy of a territory is not only related to attraction factors and suitable accommodation facilities, but also depends on an adequate transport system; system able to facilitate access to tourist sites, ensuring quality in transport services. The coordinated promotion of investments in the tourism sector and of investments in infrastructure and transport services could facilitate greater access to the sites and the reduction of the general travel cost. In this sense, the analysis of transporttourism interconnections could be a useful information tool for making general economic and sector policy choices.

The planning and implementation of actions in the transport sector pushes to analyze the mobility demand in general, and touristic mobility demand in particular, in relation to the socio-economic variables that characterize a region and the performance of the transport system. On the other hand, tourist policies cannot neglect the aspects related to the management of travels towards regions of interest (longhaul) and within the same regions (local trips).

The paper therefore proposes a brief review of reference models taken from the specialized literature for integrated Transport/Tourism analyses (transport/land use models, demand models, supply models, etc.). Attention is focused especially to accessibility models. A theoretical approach to accessibility analysis is proposed, which tends to include both travel cost factors and tourist attraction factors. An application of the modelling approach is then presented, with reference to two Mediterranean regions, Calabria and Crete, and to the international tourism context, useful to highlight the role of the different components at stake, also in relation to some scenario hypotheses. Finally, some remarks on the analytical approach adopted and on possible future research developments are proposed.

\section{TRANSPORT AND TOURISM. STATE OF} THE ART ABOUT MODELLING APPROACHES

Understanding how tourists move through time and space, and the factors that influence their movements, has important implications for infrastructure and transport development, product development, destination planning, and the planning of new attractions, as well as management of the social, environmental and cultural impacts of tourism. The interaction between tourism and transport has been subject of studies for a long period of time [3].

Quantitative researches able to measure the impacts of transportation on tourism are based on CGE, Computable General Equilibrium [4]. A CGE model is a system of equations describing an economy as a whole, the interactions among its parts, the motivations and behaviors of all producers and consumers in the economy, and the linkages among them [5]. CGE models may be used to tourism analysis, and to simulate the inter-relationships among tourism and other sectors of the domestic economy, to different economic scenarios [6].

The analysis of touristic mobility can be tackled by adopting transport models. Some approaches consider the question at land use/transportation level, others focus just the usual dimensions of trip (origin, destination, modal choice, path) limiting the attention to the touristic motivation.

The Fig -1 shows a simplified scheme useful to frame the problem. Given a territory, it is possible to distinguish a transport system and a system of activities (socio-economic) that interact mutually. Within the transport system it is still possible to distinguish two macro-components, supply and demand; the interaction between these two components results in traffic flows on the transport network and in network performance (service levels, transport quality, external impacts). The activity system influences the transport demand and, in turn, undergoes the influence of the transport system structure, through accessibility. Indeed, a good transport system improves accessibility to the territory.

The analyst's attention may be limited to a component of the activity system, i.e. the tourism component; in this case the structure of a regional tourism system generates the tourist mobility demand, but the growth capacity of the tourism system is linked to the transport supply, through accessibility. The latter can be influenced by the tourism system of the region through attractiveness factors. The enhanced quality of related tourism services, as information and communication, booking, restaurants, accommodation, might improve the accessibility of the destination, and can also affect tourists' preferences. 


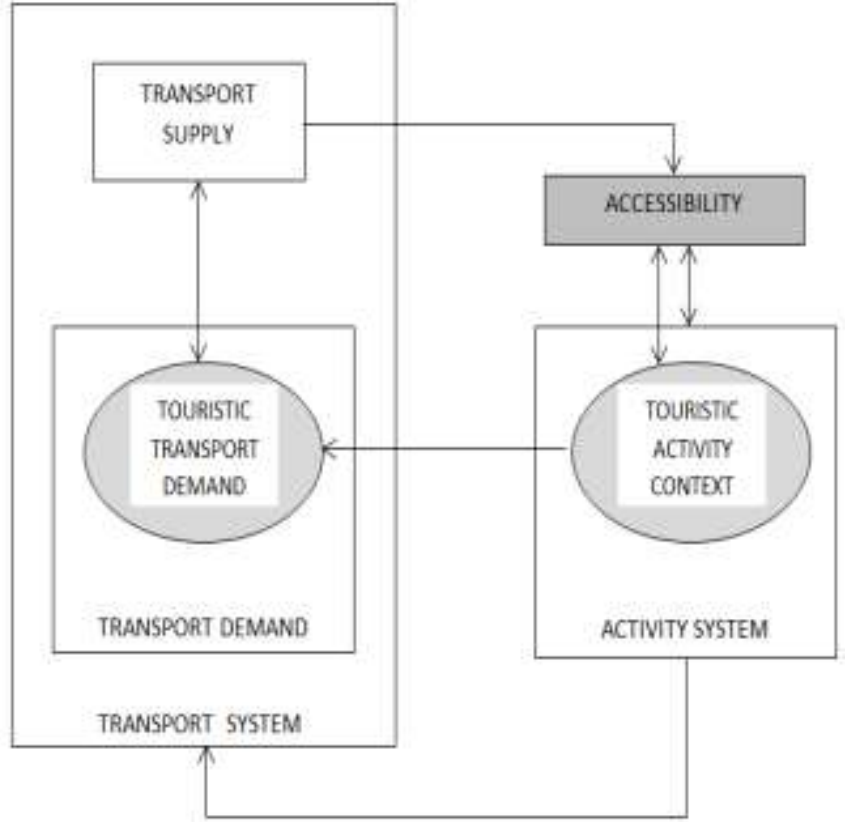

Fig -1: Touristic components in Land Use activities and Transport system

There are many studies concerning the Transport/Land Use dimension; states of the art have been proposed by different authors [7]; [8]; [9]; [10] but related to the tourism/transport sector they are rarer. The interactions between tourism and transport have been studied by some scholars [11];[12]; there are also specific researches related to the estimation of the demand for touristic mobility [13]; [14]; [15] and the demand/supply interaction in the tourism sector. The majority focuses on forecasting models and econometric approaches. Matching supply and demand in tourism has been analyzed from different perspectives [16], such as tourists' motivations and destination choice [17], tourist perceptions of destinations [18], destination attractiveness [19].

The typical transportation model subdivides a territory into relatively homogenous land-use zones, and express the demand for couples of zones in a specific interval of time (hour, day, year). For the tourism industry, it is possible to distinguish two different land context:

- An interregional or international context, where tripgenerating zones are states or regions and the destinations consist of a range of potential attractive regions, land or cities; in this case the touristic flows occur between specific points as airports, train/bus stations, ports, or origin/destination sites using car as mode of transport;

- A local context; trip generating zones tend to be highly concentrated areas of hotels and resorts, as well as more dispersed second homes and those of friends and relatives; like workday commuters, the overall flow of tourists will occur out from these points of origin in the morning, and return to them at the end of the day (similar to a hub-and-spoke pattern).
An important element in touristic mobility modelling is the transportation network, which includes the alternative routes from the different origin/destination couples. The network depends of type and distance of travel and of the modal opportunities available; transportation modelling is useful to predict the distribution of trips among different transportation modes. The choice of transport mode considers two factors: a practical one relating to forms of transport available and a perceptual one relating to the perceived related costs and benefits. Basic modes are available: car, airplane, train, bus, ship; and, at local context public means (buses, trams, trains, ferries, taxis), bike, walking. The two most important modes of travel serving tourism are today air travel and the private motor car.

A specific field of research concerns territorial accessibility measures. Some studies focus the attention only on the transport supply, considering the role of transportation in tourism essentially to provide accessibility [20]. Without accessibility, tourism simply cannot take place [21]. Accessibility is not only defined as providing opportunity to tourists to reach destinations, but also by the use of transportation services at destinations once they arrive [22]; [23]; [24] assess the attractiveness of tourist destinations through Six A's, as follows: (i) Accessibility of the destination; (ii) Attractions, defined as the local sights that attract demand; (iii) Accommodation structures; (iv) Amenities, or the services available at the destination (restaurants, theatres, etc.); (v) Assemblage, or the activity of tour operators/local actors to generate complex offers; (vi) Ancillary services, which include the activities of incoming agencies, local institutes, and supporting organizations. Among these factors, accessibility is stressed as the fundamental element that determines the destination's position in the market.

In general, a tourist destination's accessibility can also be improved by developing the transportation infrastructure network or by improving connectivity between the network and tourist facilities. In some exceptions, improving transportation infrastructure may reduce accessibility [25]. Cost is a major consideration determining the demand for a destination. It generally includes two components: travel cost (monetary and temporal) and living cost at the destination.

\section{THEORETICAL APPROACH}

The Transport/Tourism synergy can induce positive effects on the economic development of a region. The coordinated promotion of investments in the tourist industry and in facilities and services of transport may encourage a better access to the sites and the reduction of the generalized travel cost. In this regard, the analysis of the integrated Transport/Tourism system, by specific accessibility models, may represent a decision system tool to orient choices of general and sectorial economic policy. 
The most known accessibility indicators are those established from the cost function associated with a transport network. Given a system consisting of a land, subdivided into $n$ zones, and the relative road network, the matrix of minimum paths can be considered the starting point for accessibility measures. The rows of this matrix correspond to the set of origin nodes and the columns to the set of destination nodes; the matrix elements, expression of the impedance function $c_{i j}$, constitute the indices of relative accessibility, that is the measure of the cost to overcome the spatial separation between each pair of nodes $i$ and $j$ on the land:

$$
a_{i j}=c_{i j}
$$

where $c_{i j}$ can indicate the distance or travel time or the cost of transportation from the zone $i$ to the zone $j$. The sum of the elements of the $i$ line $i$ of the minimum path matrix, on the other hand, provides the value of nodal accessibility relative to the zone $i$. It constitutes the minimum total impedance for the movements from the zone $i$ to all the other zones, i.e. the integral accessibility index referring to the zone $i$, which expresses the connection of the zone $i$ with the surrounding land (zones $j$ ) :

$$
A_{i}=\Sigma_{i} a_{i j} \quad j \in D
$$

where $D$ represents the set of $n$ destination zones of the trips. The full accessibility index, introduced in 1971 by Ingram as an extension of the relative accessibility measure, makes possible to compare the accessibility level of the different zones belonging to the region $D$. The highest value of the $A_{i}$ will belong to the zone of the less accessible zone.

\subsection{Accessibility in Interspatial Models}

The mathematical measures of accessibility that express the potential of the transport system, seen above, are functions only of the travel cost variable; in reality, experience shows that other factors contribute to determining the possibility to travel from the $i$ zone to the $j$ zone. These factors are linked to the system of local activities such as job opportunities, transport level of services, accommodation, factors that can act in defining the impedance function. Beyond the different theoretical formulations, an aggregate measure can be summarized with a single formulation:

$$
A_{i}=\Sigma_{j} K_{j}^{\beta} \Phi\left(c_{i j}\right)
$$

Where:

- $A i$ is the weighted accessibility for people living in zone $i$ related to the zones $j$ in region $\mathrm{D}$;

- $K_{j}$ is a measure of activities and services located in zone $j$

- $\quad \beta$ is a calibration parameter;

- $\Phi\left(c_{i j}\right)$ is an impedance function, usually decreasing with the cost $c_{i j}$, which over the years has assumed different expressions, depending on the authors.
Among the different expressions of the impedance function $\Phi\left(c_{i j}\right)$ some are mentioned here:

A. Hansen's expression (1959): $\Phi\left(c_{i j}\right)=c_{i j}{ }^{-1}$ If $\alpha=1$, the accessibility assumes the following expression:

$$
A_{i}=\Sigma_{j} K_{j}{ }^{\beta} C_{i j}{ }^{-1}
$$

The accessibility is, therefore, measured by the sum of the activities located on the region $D$, weighted with decreasing values as the transport cost increases according to the gravitational principle. $\mathrm{A} i$ thus formally corresponds to the balance factor of the gravitational distribution models bound to the origin.

B. Wilson's expression (1967): $\Phi\left(c_{i j}\right)=\exp \left[-\left(\beta_{1} t_{i j}+\beta_{2} c_{i j}\right)\right]$ The transport impedance is expressed as a linear combination of times and monetary costs, and accessibility takes the following form:

$$
A_{i}=\Sigma_{j} K_{j} \beta \exp \left(-\left(\beta_{1} t_{i j}+\beta_{2} c_{i j}\right)\right.
$$

In literature it is possible to find similar alternative expressions of accessibility, as:

$$
\begin{gathered}
A i=\Sigma_{j} K_{j} \exp \left(-c_{i j} / \bar{C}\right) \\
A i=\Sigma_{j}\left(P_{j} / S_{j}\right) c_{i j}{ }^{-1} \\
A i=\Sigma_{j}\left(P_{j} / S_{j}\right) \exp \left(-c_{i j} / \bar{C}\right)
\end{gathered}
$$

Accessibility measures are computed with respect to the origin zone $i$, considering the population $P_{j}$ of region $j$ and $\left(P_{j} / S_{j}\right)$ are densities, given extension area $S_{j}$ of the zone $j ; \mathrm{c}_{\mathrm{ij}}$ is the travel cost from origin zone $i$ to destination zone $j ; \bar{C}$ is the travel cost computed as average of the different alternatives.

C. Ingram's expression (1971): $\Phi\left(c_{i j}\right)=\exp \left(-d_{i j}^{2} / \gamma\right)$

In this case the formulation of accessibility becomes:

$$
A_{i}=\Sigma_{j} K_{j} \exp \left(-d_{i j}^{2} / \gamma\right)
$$

with $d_{i j}$ the distance between the zones $i$ and $j, \gamma$ parameter of the model.

In all these expressions the problem is the attribution of values to the different parameters, because accessibility cannot be measured experimentally, i.e. the parameters cannot be calibrated on the basis of real observations. A choice can be to assume parameters by analogy, i.e. values close to those derived from phenomena that can be verified experimentally. Very common calibration methods such as the least squares method, however, appear valid only in those geographical contexts in which the flow structure is characterized by isotropy and homogeneity; on the other hand, a limit remains because such measures imply a 
deterministic behavior of individuals (all individuals in the same area have the same level of accessibility) and does not cover the different perceptions of the alternatives.

\subsection{Accessibility in Disaggregated Models}

A possible solution to overcome the unrealistic hypothesis of the deterministic behavior of individuals, implicit in interspaces models, refers to a micro-economic approach [26]; [27]. with the transition towards disaggregated expressions of the accessibility function, based on a model of choice among alternatives of random utilities in which the behavior of the individual user is envisaged. Through this approach, the probability of choosing a destination by the individual user can be estimated. In general, the travel behavior for a tourist involves different aspects:

- $\quad$ need recognition (personal, interpersonal, commercial);

- information search (about destination, travel, accommodation, etc.);

- evaluation of alternative opportunities, influenced by socio-psychological factors (experiences, life-cycles stages, income, available time) and by objective and subjective criteria;

- choice of the alternative, as the related perceived risks;

- consumption of the travel;

- post-experience evaluation.

Concerning the travel choice, behavior is influenced by two fundamentals questions: what motivates visitors to travel to destinations, how do visitors choose a destination. It implies analysis of different destination attributes; the choice of destination is based on different factors as travel cost and destination touristic attractiveness.

The basic hypothesis is that the user behaves rationally. Faced with the desire to make a travel, considering all the available alternatives that constitute his set choice, he will select the perceived alternative location as the one of maximum utility. The visitor $f$, living in a zone $i$ of a region $\mathrm{D}$, is able to associate to the travel towards each alternative zones $\mathrm{j}$ of his choice set, a perceived utility or attractiveness $U_{j f}$, which is a function of the values assumed by attributes selected to evaluate the usefulness of each alternative:

$$
U_{j f}=U_{j f}\left(X_{j f}\right)
$$

where $X_{j f}$ is the vector of the attributes of the alternative $\mathrm{j}$ for the user $f$. The attributes can be distinguished into different classes: service level attributes of the transport system (times, costs, comfort, etc.), attributes of the activity system dependent on the land use (number of activities and their types by zone), socio-economic attributes of the user or his family group (driving license, number of cars owned by the family, income, type of job, etc.).

Utility is a random variable; it is not possible to determine, in absolute way, the alternative selected by the user, as users with the same socio-economic characteristics may be differently sensitive to the same attributes. The utility $U_{j f}$ can be decomposed into a deterministic mean component $V_{j}$, also called systematic utility and a random component $\varepsilon_{j}$ :

$$
U_{j f}=V_{j}\left(X_{j f}\right)+\varepsilon_{j} \forall j \in I_{f}
$$

with $I_{f}$ set of choice alternatives.

Assuming that the random components are distributed with a probabilistic Gumble Distribution, also the utilities $U_{j}$ are variables of Gumble and the maximum utility perceived is:

$$
U_{\text {max }}=\log \Sigma_{j} e^{V j}
$$

In particular, assuming:

$$
V_{j}=\beta_{0} \log K_{j}-\beta_{1} c_{i j}-\beta_{2} t_{i j}
$$

where $K_{j}$ is the number of activities in the zone $j, c_{i j}$, and $t_{i j}$ are respectively cost and travel time between $i$ and $j$, it is possible to write:

$$
\begin{gathered}
V_{j}=\log \left[K_{j} \beta 0 \exp \left(-\beta_{1} c_{i j}-\beta_{2} t_{i j}\right)\right] \\
\left.A_{i}^{*}=\Sigma_{j} V_{j}=\log \Sigma_{j}\left[K_{j}^{\beta 0} \exp \left(-\beta_{1} c_{i j}-\beta_{2} t_{i j}\right)\right]\right]=\log A_{i}
\end{gathered}
$$

The total utility for the user coming from the zone $i$, is equal to the natural logarithm of the accessibility of the zone $i$ expressed in the inter-spatial model of Wilson. Accessibility can therefore be used as a measure of the social benefits associated with a given region $i$.

In analogy, it is possible to express the total utility for the destination region $j$, as sum of systematic utilities for users directed to the zone $j$ :

$$
\left.A_{j}^{*}=\Sigma_{i} V_{j}=\log \Sigma_{i}\left[K_{j}^{\beta 0} \exp \left(-\beta_{1} c_{i j}-\beta_{2} t_{i j}\right)\right]\right]=\log A_{j}
$$

\subsection{Accessibility as a Measure of Freedom of}

\section{Individual Movement}

By adopting the representation of the human activities of [28], the activities of an individual can be described by a trajectory in space and time. Each event in the life of an individual can therefore be represented with spatial and temporal coordinates; in particular, the position occupied by an individual at any moment will be represented in space with two geographical coordinates and one temporal one.

The advantage of this representation is that it allows us to reveal how the different constraints (technological, participation, social, physiological) limit the participation of individuals in the different activities [29].

\section{ACCESSIBILITY APPROACH TO VALUATE TOURISTIC DEVELOPMENT POLICY}

The accessibility index may be used as a measure of the impacts on a given region, consequent to the application of 
specific strategies addressed to touristic development. For this purpose, a disaggregated model was adopted in which the total utility for the destination region $j$, is the sum of systematic utilities for users directed to the zone $j$.

This model was adopted in consideration of following elements:

- the context is international;

- a large data-base has been built concerning the air transport supply, the demand for tourist mobility and the activity system of the destination regions of interest;

- some weighting parameters of travel attributes are available from the specialized literature.

Two types of systematic utility functions (or generalised cost functions) have been firstly considered; the one with two attributes, time $\left(t_{i j}\right)$ and monetary cost $\left(c_{i j}\right)$ for origin/destination pair $(\mathrm{O} / \mathrm{D})$, the other including a third attribute, the flight frequency $\left(f_{i j}\right)$, on the same pair O/D:

$$
\begin{gathered}
V_{j}=-\beta_{1} c_{i j}-\beta_{2} t_{i j} \\
V_{j}=-\beta_{1} c_{i j}-\beta_{2} t_{i j}-\beta_{3} f_{i j}
\end{gathered}
$$

The analysis has been extended to consider the potential attraction of the destination area $j$, through an attribute $K j$ expression of tourist accommodation and an attribute $W_{j}$ expression of the attractive opportunities of the region (cultural sites, museums, archaeological areas, etc.), and a parameter $\delta$ as a marketing (promotional) factor.

In the case (1), the systematic utility will be:

$$
\begin{gathered}
V_{j}=\beta_{0} \log K_{j}-\beta_{1} c_{i j^{-}} \beta_{2} t_{i j} \\
V_{j}=\beta_{0} \log \left(K_{j}+\delta W_{j}\right)-\beta_{1} c_{i j^{-}} \beta_{2} t_{i j}
\end{gathered}
$$

In the case (2), instead:

$$
\begin{gathered}
V_{j}=\beta_{0} \log \left(K_{j}\right)-\beta_{1} c_{i j}-\beta_{2} t_{i j}-\beta_{3} f_{i j} \\
V_{j}=\beta_{0} \log \left(K_{j}+\delta W_{j}\right)-\beta_{1} c_{i j}-\beta_{2} t_{i j}-\beta_{3} f_{i j}
\end{gathered}
$$

In other words, the expressions (3) - (6) can be written as:

$$
\begin{gathered}
V_{j}=\log \left[K_{j}^{\beta^{0}} \exp \left(-\beta_{1} c_{i j}-\beta_{2} t_{i j}\right)\right] \\
V_{j}=\log \left[\left(K_{j}+\delta W_{j}\right)^{\beta^{O}} \exp \left(-\beta_{1} c_{i j}-\beta_{2} t_{i j}\right)\right] \\
V_{j}=\log \left[K_{j}^{\beta^{O}} \exp \left(-\beta_{1} c_{i j}-\beta_{2} t_{i j}-\beta_{3} f_{i j}\right)\right] \\
V_{j}=\log \left[\left(K_{j}+\delta W_{j}\right)^{\beta^{0}} \exp \left(-\beta_{1} c_{i j}-\beta_{2} t_{i j}-\beta_{3} f_{i j}\right)\right]
\end{gathered}
$$

Finally, the accessibility index for a destination region $j$ will be:

$$
A_{j}^{*}=\Sigma_{j} V_{j}=\log \Sigma_{i}[\ldots \ldots \ldots . .]
$$

\section{AN APPLICATION TO A MEDITERRANEAN REGION}

In Italy the tourism sector registered positive results in the last years. The wealth produced by this expenditure is polarized in 5 regions - Lazio, Lombardy, Veneto, Tuscany and Emilia Romagna - where 67,5\% of expenditure of foreign tourists and $63 \%$ of tourism value added are concentrated. Despite the significant recent improvement, Southern Italy is still marginal. There are many attractiveness factors of the Southern regions (environment and weather; landscapes variety; archaeological sites and historical villages; cultural, monumental, artistic heritage; gastronomy, long and variegated coasts, etc.); except for some limited spatial contexts, the tourism industry, however, appears still weak, mainly seasonal, anchored to the past and to organizational models unable to meet international demand. For this reason Italy has structural difficulties in positioning itself on emerging markets and, in general, with regard to the new demand flows. The main results of impact analysis of the Italian tourism sector on national GDP were analyzed by a specific model (MiBACT, 2017); according to this model, the percentage of total national GDP produced by tourism is $11,8 \%$ (171 bn $€$ ) and the impact on employment is around $12,8 \%$ (3.1 million jobs).

A strategic national Plan for tourism (PST 2017-2022) has been recently implemented by Ministry of Culture and Tourism - MiBACT, according to three overarching principles:

- Sustainability (reinforcement of tourism in relation to environment, landy, protection of heritage, socioeconomic system, culture and citizenship);

- Innovation (of the products, processes, technologies and organization of tourism activities; of the market and methods, creating new and more advanced skills);

- Physical and cultural accessibility/permeability (accessibility of all people; sustainable mobility systems; opportunity for visitors to understand and interpret the history, complexity and variety of the sites).

In a logical of cooperation strategy, supporting the PST, recently a Tourist Mobility Plan has been elaborated in 2017 by Ministry of Infrastructure and Transport, in order to improve tourist mobility, through definition of targets shared with sector operators and the main stakeholders. Some actions are envisaged in a soft mobility plan and some strategic projects were identified to realize a slow network, including cycle routes, roads, historical railway lines, integration between railway services and tourism activities. It is also planned to encourage intermodality, starting with the main gateways to the system of international flows of tourists (airports, ports, etc.); to ensure local accessibility to the country's tourist destinations and the areas' permeability; to enhance infrastructural heritage as part of the overall strategy to make the regions attractive and promote their sustainable development. 
The awareness that the national tourism industry can grow through an appreciation of the potential of Southern Italy has led to assume as a case study in terms of accessibility, one of the poorest European regions, Calabria region, with significant resources related to environment, history, culture, archaeology. Calabria has a remarkable historicalmonumental heritage linked to the Magna Graecia and to the Byzantine eras. The application, in the context of international tourism, is also extended to a second Mediterranean region, the Greek region of Crete, for comparative purposes in order to highlight the role of the different components at stake (supply in terms of transport and attractive factors, also in relation to scenario hypotheses).

Table -1 shows some characteristic attributes of the two regions; Calabria has a double extension compared to Crete and a triple population. GDP per capita is similar. The supply of Calabria's networks is much greater both in terms of roads and railways; in Crete there is no rail transport and the motorways are still under construction. The density of marinas, in relation to the length of the coastline, is roughly double in Crete. In both regions there are 3 airports, but in Crete two of them are international, while in Calabria there is only one. Tourist accommodation on the Greek island is almost double. Fig -2 and Fig -3 highlights the extension of the two regions, the main networks and the position of the airports.

Table -1: General data of the activity and transport system

\begin{tabular}{|l|l|l|}
\hline Indicators & Calabria & Crete \\
\hline Area $\left(\mathrm{km}^{2}\right)$ & 15.222 & 8.336 \\
\hline Population & 1.958 .296 & 623.065 \\
\hline GDP per-capite $(€)$ & 14.529 & 14.445 \\
\hline Railway $(\mathrm{km})$ & 852 & 0 \\
\hline Roads $(\mathrm{km})$ & 1.924 & 496 \\
\hline Motorway $(\mathrm{km})$ & 294 & 65 \\
\hline Airports & 3 & 3 \\
\hline Marinas & 16 & 13 \\
\hline Accommodation & 3.454 & 5.765 \\
\hline Beds ${ }^{(*)}$ & 187.764 & 313.393 \\
\hline
\end{tabular}

(*) Crete: estimated value.

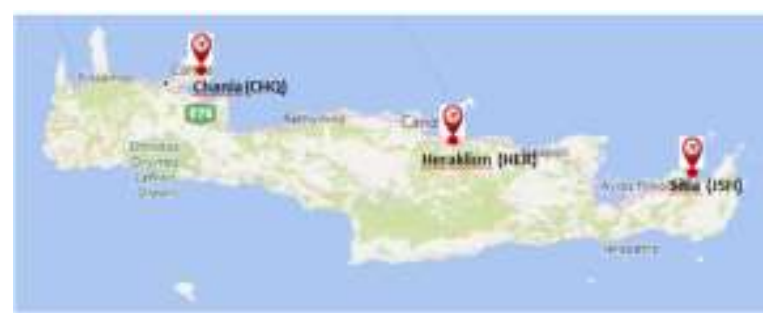

Fig -2: Crete region. Airports sites

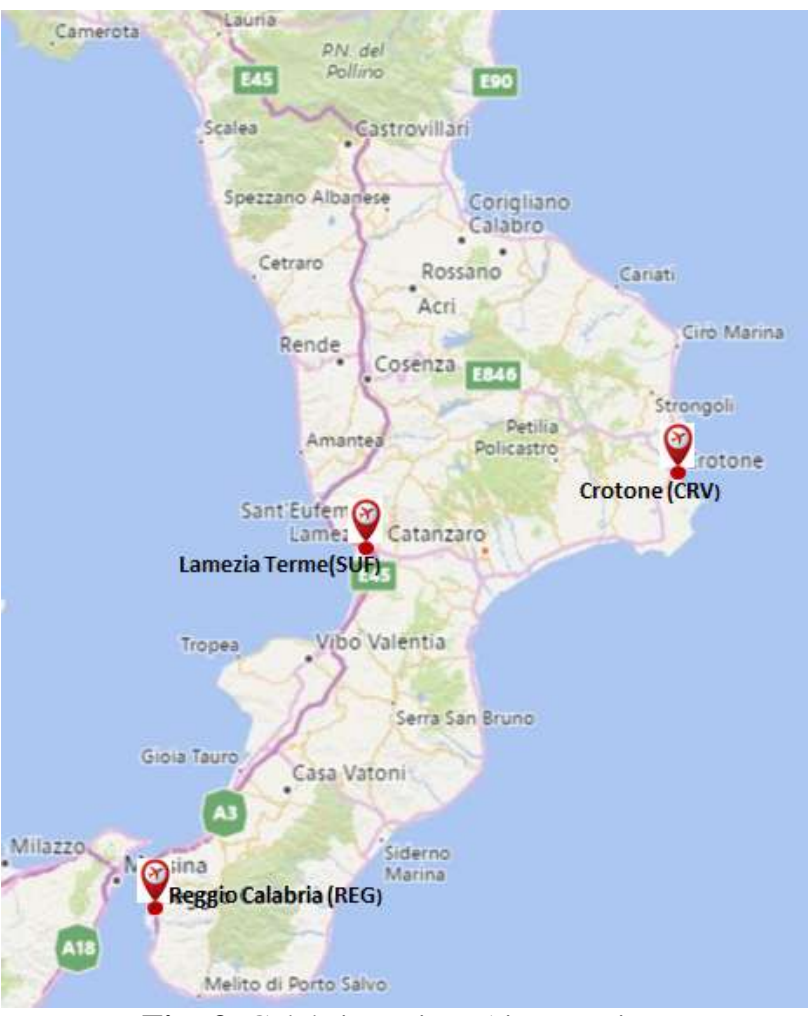

Fig -3: Calabria region. Airports sites

Since the interest is focused on international accessibility, some data relating to the air transport in 2016 (Table -2) have been acquired, in particular those concerning the main airports of the two regions (LameziaTerme in Calabria, Heraklion in Crete). The differences do not seem relevant in terms of operating airlines and the number of connected cities; in reality the supply differences are more consistent in terms of flight frequency, especially in the high season, and in terms of direct connection, to the advantage of Crete. It is not random that the difference in terms of passengers is relevant: Heraklion has a more than double transport demand.

The difference in terms of passengers transported is noteworthy even observing the overall regional context, with passenger traffic in Calabria of 3.2 million passengers and traffic of 9.7 million passengers for Crete, about a triple volume. A relevant component of the aerial traffic is the touristic demand, especially for Crete region.

Table -2: Supply and demand data for air transport Year 2016

\begin{tabular}{|l|l|l|}
\hline & $\begin{array}{l}\text { Lamezia T. } \\
\text { (Calabria) }\end{array}$ & $\begin{array}{l}\text { Heraklion } \\
\text { (Crete) }\end{array}$ \\
\hline Airlines & $\begin{array}{l}34(29 \text { in high } \\
\text { season) }\end{array}$ & $\begin{array}{l}\text { 37 (28 in high } \\
\text { season) }\end{array}$ \\
\hline Flights & 21.856 & 50.754 \\
\hline Connected cities & 86 & 82 \\
\hline Passengers & 2.521 .781 & 6.867 .957 \\
\hline Runways & 1 & 2 \\
\hline
\end{tabular}


For the purposes of the accessibility analysis, 5 international relationships were analyzed for Lamezia and Heraklion airports, taking as origin cities for tourist trips 5 European capitals (Paris, Berlin, Moscow, London, Zurich). The analysis was carried out with reference to the month of August, the peak holiday period. From Fig -4 it is possible to see that connections to Crete are all direct, while on LameziaTerme an intermediate stop is necessary (Milan).

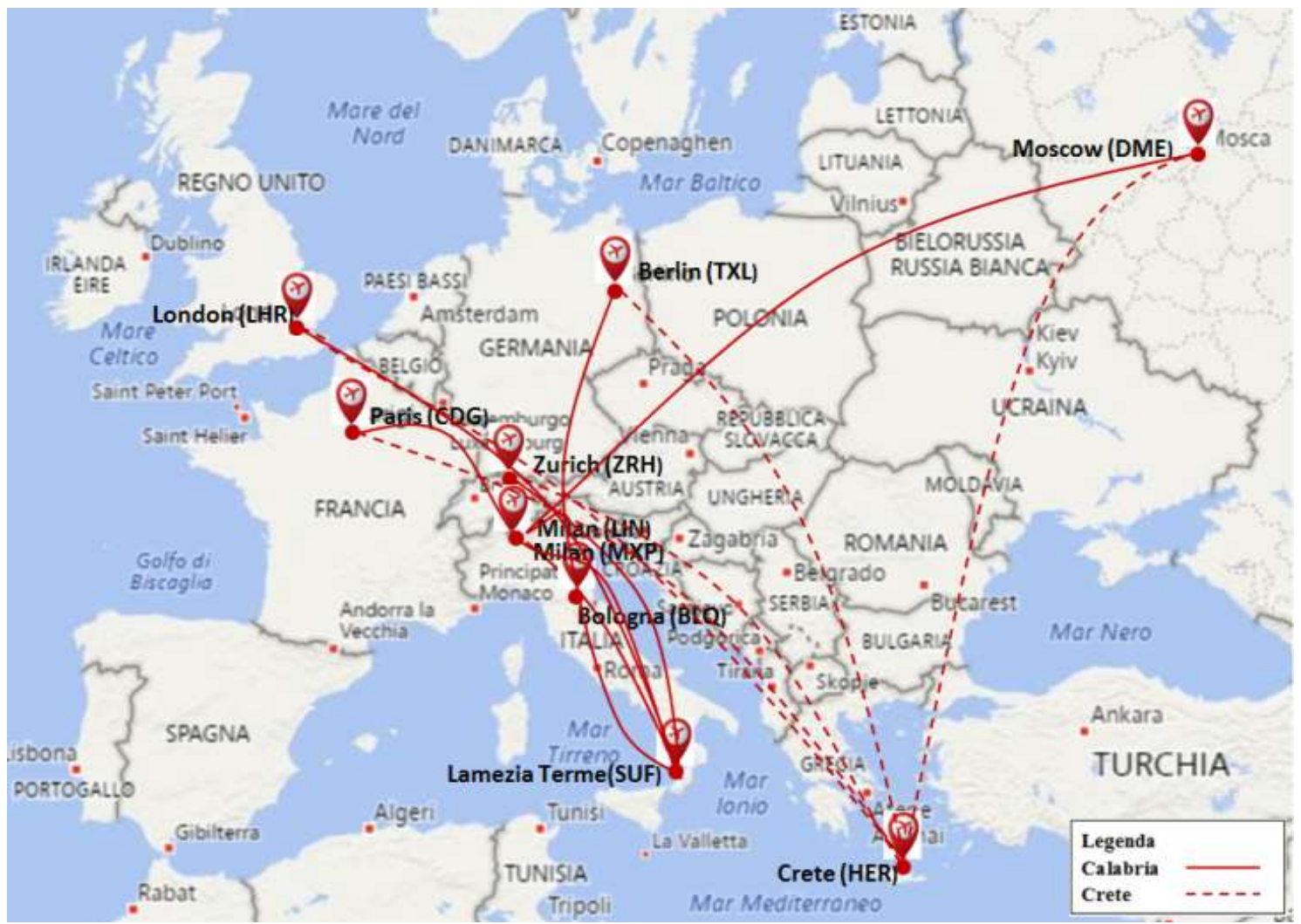

Fig -4: Flights connections from 5 Europeans capitals to Crete and Calabria regions

The air transport supply, day by day, of a representative week (the second week of August 2018) was analyzed in detail; individual travel costs, travel times including stops in intermediate airports, flight frequencies were acquired.

Table -3 shows a synoptic picture of the supply and demand for air transport over the $10 \mathrm{O} / \mathrm{D}$ considered relationships in terms of average travel time $(h)$, travel fare $(€)$ and number of weekly flights. It also presents the weekly tourist passenger traffic for each relationship.

Table -3: Supply and demand data for air transport. Week of August

\begin{tabular}{|l|l|l|l|l|l|}
\hline Origin & Destination & $\mathrm{t}(h)$ & $\mathrm{C}_{\mathrm{m}}(€)$ & Flights & Tourists \\
\hline Paris & Lamezia T. & 4,1 & 132 & 74 & 750 \\
\hline Berlin & Lamezia T. & 5,4 & 85 & 65 & 659 \\
\hline Moscow & Lamezia T. & 7,0 & 127 & 44 & 446 \\
\hline London & Lamezia T. & 3,7 & 115 & 82 & 831 \\
\hline Zurich & Lamezia T. & 2,1 & 126 & 68 & 689 \\
\hline Paris & Crete & 3,6 & 96 & 68 & 3013 \\
\hline Berlin & Crete & 3,4 & 97 & 52 & 2304 \\
\hline Moscow & Crete & 3,8 & 127 & 43 & 1905 \\
\hline London & Crete & 3,9 & 112 & 68 & 3013 \\
\hline Zurich & Crete & 3,1 & 142 & 46 & 2038 \\
\hline
\end{tabular}

In order to evaluate the effect of variations in scenario contexts, starting from the supply and demand data for a whole week, an aggregated demand transport model has been derived through an appropriate interpolation of the same data; it express the dependence of transport demand $\left(T D_{j}\right)$ from related systematic utility $V_{j}$ (or generalized cost);

In the generalized cost functions, $\beta_{1}$ is equal to $1, \beta_{2}=50 € / \mathrm{h}$ for touristic aerial travel [31]. In equation (2) the flight frequency attribute was considered as a dummy variable $(Y)$ which is worth $200 €$ in the case of absence of direct flights over a period of one week, 0 in the case of daily direct flights and assumes inversely proportional intermediate values in relation to the frequency from 1 to 7 . The formula (2) becomes:

$$
V_{j}=-\beta_{1} c_{i j}-\beta_{1} t_{i j}+Y
$$

According to the formula (12), the following transport demand function was carried out:

$$
T D_{j}=4.155,1 \exp \left(-0,003 V_{j}\right)
$$

The demand indicator is useful to analyse how the variations in accessibility (in terms of generalized cost) influence the 
mobility demand. The goodness of data fit is given by the coefficient of determination, R-squared measure, equal to 0,47 .

\subsection{Accessibility Analysis}

Subsequently, the analysis of accessibility from the cost function (5) was carried out. In the analysis the potentials of the destination region $j$ is expressed through $K_{j}$, an attribute of tourist accommodation capacity (Table -4).

Table -4: Accessibility simulation

\begin{tabular}{|l|l|l|l|l|l|l|}
\hline Origin & $\begin{array}{l}\text { Destinatio } \\
\mathrm{n}\end{array}$ & $\mathrm{t}(h)$ & $\begin{array}{l}\mathrm{c}_{\mathrm{ij}}(€ \\
)\end{array}$ & $\begin{array}{l}\mathrm{Y}(€ \\
)\end{array}$ & $K_{j}$ & $V_{j}$ \\
\hline Paris & Lamezia T. & 4,1 & 339 & 200 & $\begin{array}{l}345 \\
4\end{array}$ & $\begin{array}{l}201 \\
4\end{array}$ \\
\hline Berlin & Lamezia T. & 5,4 & 353 & 175 & $\begin{array}{l}345 \\
4\end{array}$ & $\begin{array}{l}203 \\
8\end{array}$ \\
\hline Moscow & Lamezia T. & 7,0 & 477 & 200 & $\begin{array}{l}345 \\
4\end{array}$ & $\begin{array}{l}175 \\
5\end{array}$ \\
\hline London & Lamezia T. & 3,7 & 301 & 75 & $\begin{array}{l}345 \\
4\end{array}$ & $\begin{array}{l}237 \\
2\end{array}$ \\
\hline Zurich & Lamezia T. & 2,1 & 233 & 75 & $\begin{array}{l}345 \\
4\end{array}$ & $\begin{array}{l}235 \\
8\end{array}$ \\
\hline Paris & Crete & 3,6 & 275 & 0 & $\begin{array}{l}576 \\
5\end{array}$ & $\begin{array}{l}438 \\
1\end{array}$ \\
\hline Berlin & Crete & 3,4 & 269 & 0 & $\begin{array}{l}576 \\
5\end{array}$ & $\begin{array}{l}440 \\
6\end{array}$ \\
\hline Moscow & Crete & 3,8 & 316 & 0 & $\begin{array}{l}576 \\
5\end{array}$ & $\begin{array}{l}420 \\
3\end{array}$ \\
\hline London & Crete & 3,9 & 304 & 0 & $\begin{array}{l}576 \\
5\end{array}$ & $\begin{array}{l}425 \\
2\end{array}$ \\
\hline Zurich & Crete & 3,1 & 299 & 200 & $\begin{array}{l}576 \\
5\end{array}$ & $\begin{array}{l}427 \\
4\end{array}$ \\
\hline
\end{tabular}

For present condition (Scenario Zero), the Calabria and Crete accessibility value, computed by formula (11) are respectively $\mathrm{Aj}^{*}(\mathrm{Cal})=4,03$ and $\mathrm{Aj}^{*}(\mathrm{Cre})=4,33$. Crete results more accessible. And this in coherent with the data about touristic traffic.

\subsection{Scenario Analysis}

The developed models are interesting because they allow analysis and scenario assessments to be carried out. In this sense, some scenarios are proposed, aimed at evaluating the impacts of improvement actions relating to the Calabria region, leaving unchanged the situation concerning Crete region. In particular, the following actions have been envisaged to improve the Calabria accessibility:

- Scenario A: reduction of travel time and introduction of daily direct flights from European capitals;

- Scenario B: increase in tourist accommodation in the region;

- Scenario C: combination of scenarios A and B;

- Scenario D: as scenario C, adding touristic promotional measures, through the attribute $\mathrm{Wj}$.
Scenario A. Table -5 shows the variation of travel time component (before-b; after-a) and the related generalized cost $\left(V_{j}\right)$. Travel times were calculated, assuming an average flight speed comparable to those of existing relationships on Crete. The daily direct flights implies $Y=0$. The global accessibilities of the two regions are: $A j^{*}(\mathrm{Cal})=4,12$ and $A j^{*}(\mathrm{Cre})=4,33$. The impact is a light improvement in Calabria accessibility, not much significant.

Table -5: Travel time reduction for Calabria destination. Accessibility impact

\begin{tabular}{|l|l|l|l|l|}
\hline Origin & Destination & $\mathrm{t}_{\mathrm{b}}(h)$ & $\mathrm{t}_{\mathrm{a}}(h)$ & $V_{j a}$ \\
\hline Paris & Lamezia T. & 4,1 & 339 & 2586,7 \\
\hline Berlin & Lamezia T. & 5,4 & 353 & 2673,5 \\
\hline Moscow & Lamezia T. & 7,0 & 477 & 2489,9 \\
\hline London & Lamezia T. & 3,7 & 301 & 2649,9 \\
\hline Zurich & Lamezia T. & 2,1 & 233 & 2755,3 \\
\hline Paris & Crete & 3,6 & 275 & 4380,8 \\
\hline Berlin & Crete & 3,4 & 269 & 4405,9 \\
\hline Moscow & Crete & 3,8 & 316 & 4203,0 \\
\hline London & Crete & 3,9 & 304 & 4251,9 \\
\hline Zurich & Crete & 3,1 & 299 & 4273,9 \\
\hline
\end{tabular}

Scenario B. Table -6 shows the variation of accommodation (before-b; after-a); it was assumed to double the accommodation capacity (number of structures) in Calabria. It is possible to observe the effects on regional accessibility. $Y$ keeps initial values. The global accessibilities of the two regions are: $\mathrm{Aj}^{*}(\mathrm{Cal})=4,33$ and $\mathrm{Aj}^{*}(\mathrm{Cre})=4,33$. The impact is a relevant increase in Calabria accessibility that brings it on par with Crete.

Table -6: Accommodation increasing in Calabria region. Accessibility impact

\begin{tabular}{|l|l|l|l|l|}
\hline Origin & Destination & $K_{j}$ & $K_{j}$ & $V_{j a}$ \\
\hline Paris & Lamezia T. & 3454 & 6908 & 4029,1 \\
\hline Berlin & Lamezia T. & 3454 & 6908 & 4076,0 \\
\hline Moscow & Lamezia T. & 3454 & 6908 & 3509,2 \\
\hline London & Lamezia T. & 3454 & 6908 & 4744,4 \\
\hline Zurich & Lamezia T. & 3454 & 6908 & 5076,1 \\
\hline Paris & Crete & 5765 & 5765 & 4380,8 \\
\hline Berlin & Crete & 5765 & 5765 & 4405,9 \\
\hline Moscow & Crete & 5765 & 5765 & 4203,0 \\
\hline London & Crete & 5765 & 5765 & 4251,9 \\
\hline Zurich & Crete & 5765 & 5765 & 4273,9 \\
\hline
\end{tabular}

Scenario $C$. The combination of the effects derived from both the actions hypothesized in the two previous scenarios 
(daily direct flights with reduction of travel time and expansion of accommodation, for Calabria, $Y=0$ ) translates into the following values of global accessibilities of the two regions: $\mathrm{Aj}^{*}(\mathrm{Cal})=4,42$ and $A j *(\mathrm{Cre})=4,34$. Calabria accessibility overcomes, even slightly, that of Crete.

Scenario D. The Scenario C evolves and in this case the influence of regional attractive opportunities (cultural sites, museums, archaeological parks, etc.) is added by the attribute $W j$, weighted by a parameter $\delta$, expression of a promotional action of policy makers. The attributeWjis equal to the main regional cultural sites (136 recorded in Calabria, 25 in Crete). A value $\delta=10$ has been adopted. The following global accessibilities values result for the two regions: $\mathrm{Aj}^{*}(\mathrm{Cal})=4,50$ and $\mathrm{Aj}^{*}(\mathrm{Cre})=4,33$. Calabria accessibility overcomes that of Crete (Table -7).

Table -7: Accommodation increasing in Calabria region. Accessibility impact

\begin{tabular}{|l|l|l|l|l|l|}
\hline Origin & Destination & $\mathrm{t}_{\mathrm{a}}(h)$ & $K_{j a}$ & $W_{j}$ & $V_{j a}$ \\
\hline Paris & Lamezia T. & 339 & 6908 & 136 & 6192 \\
\hline Berlin & Lamezia T. & 353 & 6908 & 136 & 6400 \\
\hline Moscow & Lamezia T. & 477 & 6908 & 136 & 5960 \\
\hline London & Lamezia T. & 301 & 6908 & 136 & 6343 \\
\hline Zurich & Lamezia T. & 233 & 6908 & 136 & 6596 \\
\hline Paris & Crete & 275 & 5765 & 25 & 4381 \\
\hline Berlin & Crete & 269 & 5765 & 25 & 4406 \\
\hline Moscow & Crete & 316 & 5765 & 25 & 4203 \\
\hline London & Crete & 304 & 5765 & 25 & 4252 \\
\hline Zurich & Crete & 299 & 5765 & 25 & 4274 \\
\hline
\end{tabular}

\subsection{Comparative Analysis and Discussion}

The comparison of different scenarios shows how accessibility index change subsequently to the different action plans activated by policy makers. It is possible to act reducing transport impedance in order to increase accessibility, but the accommodation capacity and touristic promotion are important too. The Chart-1 shows the index accessibility evolution for Calabria Region by present state to different Scenarios; the increasing accessibility corresponds to the extension of measures able to improve transport supply and land attractiveness. It is plausible that the better accessibility of the region pushes the increasing of tourism demand.

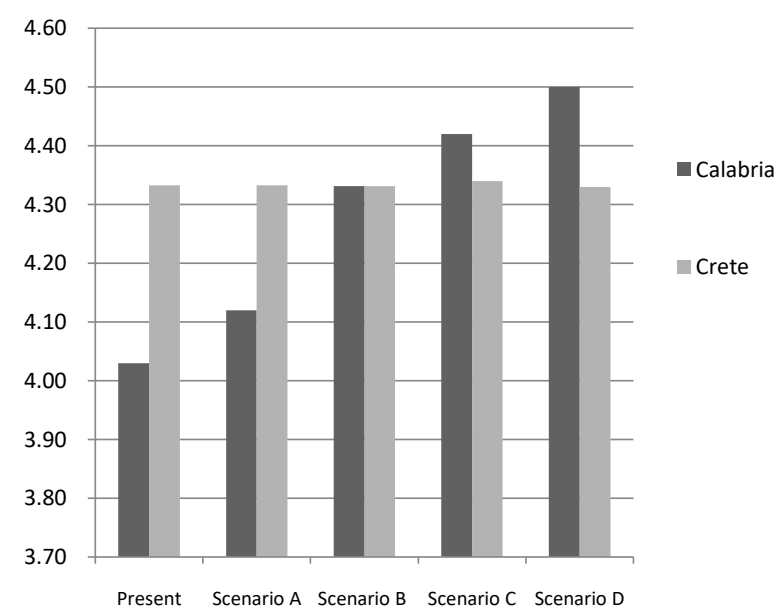

Chart -1: Accessibility regions. Compared analysis

The touristic transport demand, computed by the demand function (13) for Calabria region, considering the reduction in generalized costs (daily and direct flights) increases from 5218 to 9215 passengers/week $(+76,6 \%)$. But the R2 of the exponential transport demand function is not very satisfying; In fact there is a consistent difference between real value and estimated value in current Scenario. Certainly it is possible to explore news demand models, based on a large set of experimental data, but the trend is evident.

Other research insights could be possible. It would be interesting to appraise the influence of the local transport services in the destination regions on the choice of the potential tourists; or still the weight of the $\mathrm{f}$ transport fares. As also the evaluations after the tourist experience, to understand the effect in terms of loyalty, as in the Crete region case, in order to have significant and useful terms of comparison to drive transportation and land use planning. Specific further researches would deserve some aspects of people behaviour that today have great importance in the international tourism; the people look for the beauty and the comfort through the discovery and the sharing of the local cultures; it would be opportune to investigate such behaviours and therefore to hold them in count in the analyses of accessibility and touristic development policies.

\section{CONCLUSION}

The tourism development is tightly tied to the availability of efficient transport systems. Many planning studies and the experience show the dependence of the transport demand from the characteristic variables of the transport services. Building an infrastructure to make easier the access to a given region (highway, railway, airport) can make more attractive the same region. But the tourists presence is also tied strongly to the attraction factors of which the region is provided. So in the analyses of accessibility it is convenient to consider both the attributes of the transport supply and characteristic land use factors. 
The paper proposes a review of reference models concerning integrated Transport/Tourism analyses (transport/ land use models, demand models, supply models, etc.), but focus overall the accessibility models. A theoretical approach to accessibility analysis is proposed, including travel costs and land use attributes. An application of the modelling approach is presented, with reference to an international tourism context, able to highlight the role of the different attributes on accessibility in relation to some measures planning applied to improve the touristic attractiveness of the Calabria, a region of the South Italy. Finally, some remarks on the analytical approach adopted and on possible future research developments are suggested..

\section{REFERENCES}

[1] Holloway C. \& Taylor N. (2006). The Business of Tourism. Harlow, Prentice Hall, 7th edition.

[2] WTTC. (2017). Travel \& Tourism. Economic Impact 2017 World. Annual Update. The Authority on World Travel \& Tourism.

[3] Hall C.M. (2010). Spatial analysis: A critical tool for tourism geographies. Space place and tourism new perspectives in tourism geographies. London.

[4] Van Truong N. \& Shimizu T. (2016). The effect of transportation on tourism promotion: Literature review on application of the Computable General Equilibrium (CGE) Model. World Conference on Transport Research - WCTR 2016 Shanghai. 10-15 July 2016. Elsevier.

[5] Burfisher M. E. (2011). Introduction to Computable General Equilibrium Models. Cambridge University Press, Cambridge.

[6] Konan D. \& Kim K. (2003). Transportation and Tourism in Hawaii: Computable General Equilibrium Model. Transportation Research Record: Journal of the Transportation Research Board 1839 (January): 142-49.

[7] Wilson A.G. (1997). Land use/transport interaction models - past and future. Journal of Transport Economics and Policy, 32, 3-23.

[8] Wegener M. \&Fürst F. (1999). Land-Use Transport Interaction: State of the Art. Deliverable 2a of the project TRANSLAND (Integration of Transport and Land Use Planning.).

[9] Russo F. \&Musolino G. (2007). Urban land use transport interaction modelling: state of the art and applications (pp. 525-534). In Proceedings of XXIII Urban Transport, Brebbia C.A. (ed.), WIT Press.

[10] Acheampong R. A. \& Silva E. (2015). Land usetransport interaction modeling: A review of the literature and future research directions. Journal of Transport and Land Use 8 (3):11-38.

[11] Prideaux B. (1993). Possible effects of new transport technologies in the tourist industry in the $21 \mathrm{st}$ century. In Robbins, D., Thompson, K. (2007). Special issue on transport at tourist destinations. Journal of transport geography 15-2. Brisbane.
[12] Page S. (2005). Transport and Tourism: Global Perspectives. Harlow

[13] Lim C. (1997). Review of international tourism demand models. Annals of Tourism Research. Volume 24, Issue 4, October 1997, (pp 835-849).

[14] Page S. (1999). Transport and tourism, Harlow, Addison Wesley, Longman.

[15] Li G., Song H. \&Witt S.F. (2004). Modelling Tourism Demand: A Dynamic Linear AIDS Approach. Journal of Travel Research, 43(2), (pp. 141-150).

[16] Lubbe B., Douglas A., Fairer-Wessels F., Kruger E., Geldenhuys E. \& Francis C. (2013). Matching Tourism Supply and Demand: an analysis of how tourism products meet the needs of emerging domestic market segments in selected regions in South Africa. University of Massachusetts Amherst. Tourism Travel and Research Association: Advancing Tourism Research Globally. 2013 TTRA International Conference.

[17] Andreu L. \& Bigne' J.E. (2004).Cognitive-affective model of leisure and tourism services satisfaction. Econ Manage Notebooks 21: 89-120.

[18] Ibrahim E. \& Gill J. (2005). A positioning strategy for a tourist destination, based on analysis of customers' perceptions and satisfactions (pp.172188). Marketing Intelligence \& Planning, Vol. 23 Issue: 2.

[19] Formica S. \&Uysal M. (2006). Destination attractiveness based on supply and demand evaluations: An analytical framework. Journal of Travel Research, 44, 418-430.

[20] Van Truong N. \& Shimizu T. (2016). The effect of transportation on tourism promotion: Literature review on application of the Computable General Equilibrium (CGE) Model. World Conference on Transport Research - WCTR 2016 Shanghai. 10-15 July 2016. Elsevier.

[21] Prideaux B. (2000). The Role of the Transport System in Destination Development. Tourism Management 21: 53-63.

[22] Page S. \& Connell J. (2014). Transport and Tourism. In The Wiley Blackwell Companion to Tourism, edited by Alan A. Lew, C. Michael Hall, and Allan M. Williams, 155-67. John Wiley \& Sons, Ltd.

[23] Le-Klähn D.T. \&Hall M. C. (2015). Tourist Use of Public Transport at Destinations - a Review. Current Issues in Tourism 18 (8): 785-803.

[24] Della Corte V., Piras A. \&Zamparelli G. (2010). Brand and Image: The Strategic Factors in Destination Marketing. International Journal of Leisure and Tourism Marketing 1 (4): 358-77.

[25] Sheffi Y. (1985). Urban Transportation Networks: Equilibrium Analysis with Mathematical Programming Methods. Englewood Cliffs, N.J. London: Prentice-Hall.

[26] Domencich T.A. \& McFadden D. (1975). Urban Travel Demand: A Behavioral Analysis. North Holland Publishing: Amsterdam. 
[27] Ben-Akiva M. \&Lerman S.R. (1985). Discrete Choice Analysis: Theory and Application to Travel Demand. The MIT Press: Cambridge.

[28] Hägerstrand T. (1970). What about people in regional science? (pp. 7-21). Papers and Proceedings of the Regional Science Association, $\mathrm{N}^{\mathrm{o}} .24$.

[29] Pred A. (1977). The choreography of existence: comments on Hägerstrand's time-geography and its usefulness. EconomicGeography 53, 207-21.

[30] Struttura Tecnica di Missione. (2017). Viaggiare in Italia. Piano Straordinario per la Mobilità Turistica 2017-2022. Ministero delle Infrastrutture e dei Trasporti. Rome.

[31] MiBACT. (2017). The Strategic Plan for Tourism. PST 2017-2022. Ministero dei Beni e delle Attività Culturali e del Turismo. Rome

[32] MeunierD. \&Quinet E. (2014). Value of Time estimations in Cost Benefit Analysis: the French experience. European Transport Conference 2014 from Sept-29 to Oct-1, 2014. Transportation Research Procedia 8 ( 2015 ) $62-71$. Elsevier

\section{BIOGRAPHIES}

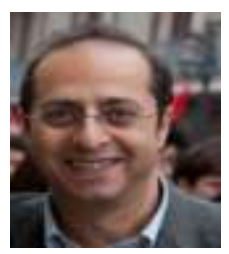

Engineer, Full Professor of Transportation Planning. Director of LOGICA Laboratory. Director of Master in Management of Transport Systems and Logistics

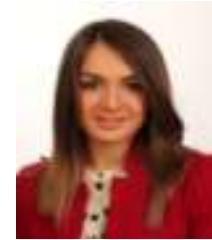

Engineer, Master's Degree in Environmental Engineering. PhD Student in Urban Regeneration and Economic Development 